\title{
GH-Producing Pituitary Adenoma: The Current Criteria of Biochemical Cure
}

\author{
Fawaz Assaad ${ }^{1 *}$, Asem Salma ${ }^{2}$ and Manar Mrad $^{3}$ \\ ${ }^{1}$ Professor of neurosurgery, Damascus University, Syria \\ ${ }^{2}$ St. Rita's Neuroscience and Rehabilitation Center, Mercy Health-St. Rita's Medical Center, USA \\ ${ }^{3}$ Department of anesthesiology, Praticien Hospitalier Hospital European Georges Pompidou, France \\ Submission: July 22, 2019; Published: August 06, 2019 \\ *Corresponding author: Fawaz Assaad, Professor of neurosurgery, Damascus University, School of Medicine, Syria
}

\begin{abstract}
It is well known that the serious systemic changes in acromegaly resulting from excess GH-secretion, and for that reason, treatment is vital. Trans-sphenoidal adenectomy has typically been the accepted initial treatment of choice for most patients with acromegaly. However, the prediction of postoperative disease activity is a major challenge, and even though different criteria for a cure have been suggested and the relationship between these criteria and long-term disease control is still controversial. According to the criteria for cure of AcromegalyConsensus, Baseline biochemical parameters for the diagnosis of acromegaly include a fasting or random GH and IGF measurement. If a random GH level is less than $0.4 \mu \mathrm{g} / \mathrm{L}$ and IGF is in the age- and gender-matched normal range, the diagnosis of acromegaly is excluded. If either of these levels is not achieved, a glucose tolerance test should be performed, the GH level should fall to $1 \mu \mathrm{g} / \mathrm{L}$ or less for acromegaly to be excluded.

In April 2009, the Acromegaly Consensus Group met to reevaluate and update the guidelines on criteria for cure. These guidelines published in 2010 summarized the latest consensus on the management of acromegaly. Therefore, optimal disease control (i.e. posttreatment remission of acromegaly) is now defined as IGF-I level (determined by a reliable standardized assay) in the age-adjusted normal range and a GH level less than $1.0 \mathrm{\mu g} /$ liter from a random GH measurement (using an ultrasensitive assay). However, assays do not consistently report these values as reflective of biochemical control. Normalization of IGF-I is the only reliable marker of disease control under pegvisomant.
\end{abstract}

Keywords: Pituitary adenoma; Acromegaly; GH-producing adenoma; IGF-1; Biochemical cure; Comorbidities; Cure criteria consensus-2000; Disease Control consensus-2010

\section{Introduction}

Acromegaly is a serious systemic condition reported in over $98 \%$ of patients with an adenoma of the pituitary gland secreting excessive amounts of growth hormone (GH). However, in very rare occasions, the increased and unregulated GH production is a result of ectopic production of GH and GHRH by malignant tumors. GH is a necessary spur for normal linear growth. However, excess secretion of GH induces gigantism in pre-pubertal children, and acromegaly in adults. GH is not the principal stimulator of growth, but it acts indirectly by stimulating the formation of other hormones. These hormones are termed somatomedins. Somatomedin C (SM-C), an insulin-like growth factor I [IGF-I]) is the most important SM in postnatal growth. SM-C is produced in the liver, chondrocytes, kidney, muscle, pituitary, and gastrointestinal tract.

The clinical features associated with acromegaly include the effects of GH over secretion and in some instances the tumor directly compressing and injuring the normal pituitary gland, optic nerves and optic chiasm. Untreated acromegaly results in specific bone and soft tissue deformation including an altered facial appearance (frontal bossing, prognathism), enlargement of the hands and feet, sleep apnea, and carpal tunnel syndrome. Severe symptoms include; an accelerated cardiovascular disease, cardiomyopathy, hypertension, diabetes mellitus, hypogonadism, and an increased risk of colon cancer. If the tumor develops before bone growth is completed in adolescence, the resulting effect is gigantism [1-3].

The diagnosis and management of complications of disease are therefore critical for assuring a favorable long-term outcome for this chronic illness.

The clinical picture of acromegaly develops insidiously, taking years or even decades to become apparent. In addition, the excess GH production leads to significant increase in morbidity and mortality additionally, and of course the mass effect of the 
pituitary tumor itself can cause several problems. Dealing with patients who develop GH producing pituitary adenoma is a challenging medical and surgical task. From surgical prospective, the hormonal functional abnormality is coupled with anatomical deviation making the surgical approach itself is quit more difficult comparing with other types of pituitary adenoma. Because of the serious systemic changes resulting from excess GH, treatment is vital. Trans-sphenoidal tumor resection has typically been the accepted initial treatment of choice for most patients with acromegaly [4-6], However, the prediction of postoperative disease activity is a major challenge, and even though different criteria for a cure have been suggested. The relationship between these criteria and long-term disease control is still controversial [7-42].

\section{Aim of therapy in GH-producing pituitary adenoma}

The current main treatment options available are; transsphenoidal microsurgical surgery, medical treatment, and radiotherapy. Surgical outcome depends on expertise of the surgeon, tumor-size, extension of the adenoma, and the preoperative level of GH. Despite surgical removal is the main treatment for GH secreting adenomas; however, some patients are not cured by surgical treatment and need additional interventions. The main aim of treatment is to remove the tumor mass, control the disease by suppressing GH hyperactivity to normal values, reduce morbidity and mortality, and eliminating secondary comorbid complications. Such control of acromegaly maybe achieved through either single or combined surgery, radiotherapy, and/or medical treatment. The biochemical goals of therapy are to reduce circulating insulin-like growth factor I (IGF-I) levels to normal for age and sex and to reduce serum GH concentration to less than $1 \mu \mathrm{g} / \mathrm{L}$ after an oral glucose load. Continuous, and long-term monitoring of the disease activity post-operatively, post medical treatment, or post radiotherapy is of high priority.

\section{Baseline Biochemical Parameters utilized in GH-pro- ducing pituitary adenoma and their pitfalls}

According to the workshop held 1999 in Cortina, Italy [10], to develop a consensus defining the criteria for cure of acromegaly [6], baseline biochemical parameters for the diagnosis of acromegaly include a fasting or random GH and IGF measurement. If a random GH level is less than $0.4 \mu \mathrm{g} / \mathrm{L}$ and IGF is in the ageand gender-matched normal range, the diagnosis of acromegaly is excluded. If either of these levels is not achieved, an oral glucose tolerance test should (OGTT) be performed with $75 \mathrm{~g}$ oral glucose and subsequent measurements of glucose and GH every $30 \mathrm{~min}$ over $2 \mathrm{~h}$. During this time, the GH level should fall to $1 \mu \mathrm{g} / \mathrm{L}$ or less for acromegaly to be excluded [11]. Failure of GH suppression after glucose loading suggests the diagnosis of acromegaly, but the results should always be considered in conjunction with an IGF-I measurement. Using all current commercial assay, the cut-off GH value separating normal subjects from those with acromegaly is less than $1 \mu \mathrm{g} / \mathrm{L}$. Care need to be taken in interpretation of the test in the immediate postoperative period due to effects of concomitant glucocorticoid administration and other perioperative medications, including glucose, dopamine, opiates, and anesthetics. The attained blood glucose levels are of importance with respect to the diagnosis of diabetes mellitus, but do not affect interpretation of the GH result.

TRH and GnRH stimulation tests of GH secretion have been used as a second-tier evaluation of abnormal GH dynamics in the diagnosis of acromegaly and in assessing responses to therapeutic intervention [12]. These tests offer no advantage over the OGTT and, as serious side effects may occasionally occur in response to $\mathrm{TRH}$, their use is not recommended for diagnosis. Although nearly all patients respond to GHRH stimulation [13], this agent is not of value in the diagnosis of $\mathrm{GH}$-secreting tumors, nor in distinguishing them from those with ectopic GHRH secretion. In suspected cases of the rarely encountered latter condition, a serum GHRH level is the preferred test. Several consensus documents have been published on various aspects of acromegaly management in and after the year 2000 [4,10,14-16]. In April 2009, the Acromegaly Consensus Group that had produced these previous documents met to reevaluate and update the guidelines on criteria for cure and published in 2010 [17] the latest consensus on the management of acromegaly.

The most importantassays used for the diagnosis, management, and monitoring of acromegaly are GH and IGF-I measurements. The lack of reliable assays, assay standardization, and adequate normative data are major issues in the interpretation of these biochemical measures. [18-21] These factors can lead to major discrepancies in the values obtained in different laboratories. The reasons for heterogeneity among GH immunoassay results include variable calibration, epitope specificity of the chosen antibody, and differences in the specificity of antibody recognition of different $\mathrm{GH}$ isoforms circulating in the serum [19]. As a first step to improving the interpretation of GH assays, it is strongly recommended that the World Health Organization (WHO) international standard (WHO IS 98/574) be used and results be expressed in mass units (micrograms per liter) [22].FormularbeginnFormularende The measurement of GH and age-matched IGF-I concentrations are the most important biochemical variables for the diagnosis of acromegaly and for monitoring progression or treatment response $[20,23,27]$.

At present it is accepted that, the measurement of total IGF-I levels reflects GH secretory status in acromegaly (at baseline for diagnosis, after neurosurgery or radiotherapy, or during medical treatment). The measurement of free IGF-I and/or IGF-binding proteins does not provide additional clinical information [2325]. In the investigation of suspected acromegaly, an elevated IGF-I level and a failure to suppress GH during an oral glucose tolerance test (OGTT) confirm the diagnosis [26]. In some cases, when the IGF-I and GH levels are clearly elevated, an OGTT may not be required [27]. Discrepant in biochemical results: According to 2010 consensus Andrea Giustina et al [17], GH and IGF-I levels are closely correlated in patients with acromegaly and healthy 
individuals [28-29] however, discordance between GH and IGF-I levels has been noted in up to $30 \%$ of patients with acromegaly after treatment [23]. Most discordance involves the measurement of normal GH levels and elevated IGF-I levels, but some cases exhibit elevated GH levels and normal IGF-I levels [30,31].

Apparent discrepant results may stem from inaccurate estimates of GH status, either from limited sampling (often a single or small number of GH measurements are obtained randomly or during dynamic testing, which may not accurately measure 24-h GH output) or from the lack of assay standardization [20]. The combination of an elevated IGF-I level and a normal GH level is sometimes seen after radiation therapy because radiotherapy causes a flat GH secretory pattern [32]. In contrast, a number of factors have been identified that can result in lower IGF-I levels relative to GH levels (either by reducing IGF-I levels or raising GH levels); these include nutritional or gastrointestinal disorders such as chronic inflammatory bowel disorder and anorexia nervosa (which can impair IGF-I production by the liver), hepatic or renal failure, oral estrogens, hypothyroidism, and poorly controlled type 1 diabetes [20].

It should be noted that the timing of postoperative testing may affect apparent discrepancies. Because of the long IGF-I half-life and other factors regulating IGF-I, it can take several months after surgery for levels to be accurate [33]. If biochemical measurements 3-6 months after surgery show an elevated IGF-I level, further testing of GH with an OGTT, multiple GH sampling (three to five times over $2 \mathrm{~h}$ ), or isolated GH measurement should be performed $[27,28,32]$. If there is a significant discrepancy, further testing may be needed over time, and therapeutic decisions should be made according to the clinical context.

\section{The Anatomical Tumor Control Prospective}

According to S. Melmed et.al [34], the role of tumor characteristics and of optimal tumor growth control has not been fully agreed by consensus. Factors proposed to be associated with disease persistence after surgery and/or a sub-optimal response to medical therapy include:

i. Younger age at diagnosis.

ii. High expression of tumor aggression markers like Ki67, p53 and pituitary tumor transforming gene.

iii. Sparsely granulated adenomas and hyper-intense imaging on T2 weighted magnetic resonance imaging.

iv. Very large adenomas and actively growing tumors.

v. No previous radiation therapy, especially during pegvisomant therapy.

vi. Previous, sub-optimal response to SRL therapy.

vii. High GH and IGF-I levels during long-term follow-up.

viii. Larger tumor remnants after surgery.

\section{Comorbidities Contribution and Consideration}

Morbidity and mortality rates in untreated and uncontrolled acromegaly are very high because of raised GH and IGF-I. Effective and aggressive long-term treatment is needed to normalize these rates. Delay in diagnosis and subsequently comorbidities are the main factors influencing the prognosis of acromegaly. Both GH and IGF-I levels correlate with mortality and mortality, and mortality is close to levels expected in the general population when $\mathrm{GH}$ and serum IGF-I are controlled. According to S. Melmed et al. [34] most of the patients with acromegaly have Cardiomyopathy, early treatment of acromegaly improves and intermediate stage myocardial hypertrophy and cardiac dysfunction. Hypertension occur in more than 40-45\% of patients with acromegaly, and early diagnosis and early aggressive treatment of elevated blood pressure is very important irrespective of the kind of treatment of acromegaly. Diabetes mellitus is the second serious complication and occurs more frequently in acromegaly patients than in the general population and is an important predictive factor for increased mortality in patients with acromegaly.

Generally, lowering of growth hormone (GH) levels improves glycemic control and enhances insulin sensitivity (GH is a powerful insulin antagonist). The prevalence of sleep apnea is very high in patients with acromegaly (over 75\%), therefore, every patient should have the necessary sleep laboratory assessment. Moreover, acromegaly is associated with increased colon polyps and may be associated with increased risk of colorectal cancer. All joints may be affected in acromegaly patients (large joints, small joints and vertebrae), and range from osteoarthritis to arthralgia to fractures together with soft tissue swelling. Early diagnosis of acromegaly is required, because joint and cartilage changes are irreversible. Visual impairment is also a symptom of acromegaly resulting from chiasmal compression in macroadenomas. Surgical decompression is the primary treatment, but SRLs may decompress mass effect when surgery is not indicated3. Effective biochemical control does not always mean optimal control of these comorbidities. Usually only partial improvement or regression may occur to these comorbidities in patients with normalized GH levels $[35,36]$.

The practical application of cure criteria for evaluating and to guide the treatment of $\mathrm{GH}$-producing pituitary adenoma

The therapeutic goals in acromegaly are to eliminate morbidity and to reduce mortality to the expected age- and sex-adjusted rates by using safe treatments that remove the tumor mass or control its growth and restore GH secretion and action to normal. The biochemical goals of therapy are to reduce circulating insulinlike growth factor I (IGF-I) levels to normal for age and sex and to reduce serum GH concentrations to less than $1 \mu \mathrm{g} / \mathrm{L}$ after an oral glucose load. The Definitive long- term remission of acromegaly was present when GH levels were less than $1 \mu \mathrm{g} / \mathrm{mL}$ and there was no clinical or magnetic resonance imaging evidence of a persisting disease. Monitoring disease activity post-operatively, post medical 
treatment, or post radiotherapy is of high priority. Nevertheless, this is not an easy mission, because the criteria to classify as an endocrinological remission are being constantly revised. For instance, in early series, GH levels $<5 \mu \mathrm{g} / \mathrm{L}$ were used to define biochemical remission. Depending on this criterion, Abosch et al. report 1998, that $76 \%$ of 254 patients had endocrinological remission after trans-sphenoidal pituitary resection [37].

In the same way, Ross and Wils found GH levels $<5 \mu \mathrm{g} / \mathrm{L}$ in $79 \%$ of 165 patients at the 76-month follow-up. However, the basal GH secretion has a pulsatile nature, therefore the GH serum level changes with sleep, age, and nutritional status of a patient [38]. For that reason, an assessment of the absolute nadir GH levels $(<2 \mu \mathrm{g} / \mathrm{L})$ after an oral glucose load was introduced and used by subsequent studies. Using these criteria, Fahlbusch et al. [39] reported a 57\% rate of endocrinological remission after trans-sphenoidal surgery. In wing years a value of nadir GH levels (GH levels $<1 \mu \mathrm{g} / \mathrm{L}$ ) was used as a more conservative criterion. Beside $\mathrm{GH}$, an additional criterion for endocrinological remission is the assessment of IGF-I serum levels. This criterion has the following advantage; it reflects integrated 24-hour GH secretion and remains relatively constant over the day. Normalization of IGF-I levels has been demonstrated following the successful treatment of acromegaly $[40,41]$.

However, the interpretation of IGF-I serum levels is more difficult than the interpretation of GH serum level, and the value of IGF-I serum level needs to be adjusted for age and gender. Assaad et al. [42]. Present a retrospective analysis of $103 \mathrm{GH}$ producing pituitary adenoma cases. Having long term postoperative random GH levels to less than $1 \mu \mathrm{g} / \mathrm{L}$ taken at multiple follow up intervals coupled with radiological evidence of total removal of the tumor were the criteria of cure. They depended on random GH level as sole method for biochemical follow up because of its simplicity in addition to some technical issues that prevent using IGF-1 in all patients, however, and order overcome the shortage of using the GH level a lone we sampled GH level multiple time randomly. This study validates - at least to some extend - the relationship between the early (in the first week after surgery) postoperative basal GH level and the long term surgical treatment outcome of GHproducing pituitary adenoma. There was a significant relationship between the early postoperative basal GH concentration and longterm postoperative outcome $(\mathrm{p}<0.05)$.

\section{Definition of cure According to the consensus from 2000}

In February 1999, a workshop was held in Cortina, Italy to develop a consensus defining the criteria for cure of acromegaly. Control is achieved when GH secretion is restored to normal. Biochemically, this is evident when circulating IGF-I is reduced to an age-adjusted normal range and nadir GH after an oral glucose load is less than $1 \mu \mathrm{g} / \mathrm{L}$. These cure criteria differ according to type of acromegaly treatment, i.e., postoperative or post medical treatment or post radiotherapy [10]. Postoperative cure in acromegaly: The goal in the transsphenoidal surgery is the complete resection of the GH-secreting adenoma, with preservation or subsequent restoration of pituitary function [43]. Surgical outcome depends on expertise of the surgeon, tumor-size, extension of the adenoma, and the preoperative level of GH. Usually postoperatively it comes to rapid reduction of serum GH levels and corresponding lowering of IGF-I levels after weeks following surgery. Patients have been classified as "cured" or "noncured." This concept was based on outcomes of surgical interventions with imprecise biochemical evaluation and is misleading for patients and clinicians. According to this consensus used for the interpretation of surgical results (GH nadir after OGTT< $1 \mu \mathrm{g} / \mathrm{L}$ ), approximately $80 \%$ of patients with microadenomas and substantially less than $50 \%$ of patients with macroadenomas can be defined as controlled [37,44-46].

On the other side after long-term somatostatin receptor ligand administration, GH levels are suppressed to less than $2.5 \mathrm{mg} / \mathrm{L}$ in $65 \%$ of patients and IGF-I levels are normalized in $70 \%$ of patients [47-49]. New slow-release formulations of long-acting somatostatin receptor ligands result in persistent GH and IGF-I suppression after IM depot injection. Drug levels peak at 28 days and are sustained for over 4 weeks. Persistently controlled mean GH levels ( $>2 \mu \mathrm{g} / \mathrm{L}$ ) are achieved in over $70 \%$ of octreotide-sensitive patients [50-51]. Acromegaly patients have delayed effect on GH levels after radiotherapy, and about $90 \%$ of patients achieve random GH levels of less than $5 \mu \mathrm{g} / \mathrm{L}$ after 18 years. Ineffectiveness of radiotherapy in lowering IGF-I despite attenuation of GH levels has been reported. However, shrinkage or at least prevention of continued pituitary tumor mass growth is usually achieved with radiotherapy. Stereotactic radiosurgery is currently under investigation, and early results show that after 1.4 years, 8 of 16 patients achieve GH levels less than $5 \mu \mathrm{g} / \mathrm{L}[51,52]$. Based on the above criteria and results, the aim of treatment is to control the disease by suppressing GH hyperactivity, reducing the size or impeding the growth of the pituitary mass, and eliminating secondary comorbid complications.

Such control of acromegaly maybe achieved through either single or combined surgery, radiotherapy, and/or medical treatment. Patients can, thus, be classified depending on the degree of disease control. Good control implies that the patient does not exhibit GH hyperactivity, as measured by available assays. Inadequate control implies the presence of GH hypersecretion, but minimally enhanced morbidity. Poor control implies that parameters of GH hyperactivity are present with a high risk of morbidity and mortality. All in all, normal IGF-I levels and a GH nadir of $<1 \mu \mathrm{g} / \mathrm{L}$ after administration of the oral glucose tolerance test (OGTT) were proposed by a consensus statement in 2000 as criteria for an acromegaly cure. By using this criterion, the endocrinological remission rates range between 57\%-67\% after microsurgical trans-sphenoidal approaches (We need references). However, when considering only pituitary macroadenomas (tumor diameter $>1 \mathrm{~cm}$ ), Nomikos et al. [53].reported an endocrinological remission in $51 \%$ of patients, as well as Beauregard et al. [41]. 


\section{Definition of Disease Control according to the 2010-consensus}

In April 2009, the Acromegaly Consensus Group that had produced previous documents met to reevaluate and update the guidelines on criteria for cure. The meeting was sponsored by the Pituitary Society and the European Neuroendocrine Association and included endocrinologists and neurosurgeons skilled in the management of acromegaly [18]. Most of the case series [30,31,54] published in the last decade have suggested that use of the Cortina criteria [10] for defining disease control could have two main drawbacks: first, they were not sufficiently flexible to be applied to different treatment modalities; and second, cutoff limits for GH did not reflect the now widespread availability of ultrasensitive $\mathrm{GH}$ assays. These guidelines published in 2010 summarized the latest consensus on the management of acromegaly. Therefore, optimal disease control (i.e. posttreatment remission of acromegaly) is now defined as IGF-I level in the age-adjusted normal range and a GH level less than $1.0 \mu \mathrm{g} /$ liter from a random $\mathrm{GH}$ measurement [55]. However, assays do not consistently report these values as reflective of biochemical control. Normalization of IGF-I is the only reliable marker of disease control under pegvisomant [56].

During follow-up after neurosurgery or radiotherapy, controlled GH status can be defined as GH suppression during an OGTT (for patients not receiving medical therapy) and a normal IGF-I-level (after 3-6 months for those that have undergone neurosurgery) [26]. When there is discrepancy between GH and IGF-I values, multiple GH sampling (three to five times over $2 \mathrm{~h}$ ) is helpful [57]. For patients receiving medical treatment with a somatostatin receptor ligand (SRL) or dopamine agonist, IGF-I and random GH measurements are enough for assessment. In fact, an OGTT may not be helpful for monitoring response in patients receiving any medical treatment $[20,26]$. In patients receiving a GH receptor antagonist, only IGF-I should be measured [58]. When surgery does not achieve control of tumor mass, medical therapy is the choice of therapy. The role of medical therapy in achieving tumor shrinkage is less well defined. In patients receiving SRL therapy, a detectable degree of shrinkage (after 4-12 months) is seen in up to $80 \%$ in some treatment series [41,57,59-62]. Tumor shrinkage is not necessarily associated with biochemical remission. There is still no clear evident that presurgical use of SRLs may improve surgical outcome [63-66].

At present, there is no longer justification for staging the outcome of treatment in acromegaly, except to define active disease and controlled disease. In summary, we talk about active disease when random $\mathrm{GH}>1 \mu \mathrm{g} / \mathrm{L}$ and nadir GH after OGTT $>0.4$ $\mu \mathrm{g} / \mathrm{L}$ together with elevated IGF-I, and controlled disease when Random GH $<1 \mu \mathrm{g} / \mathrm{L}$, or nadir GH after OGTT $<0.4 \mu \mathrm{g} / \mathrm{L}$ together with Age-sex normalized IGF-I. Despite these guidelines, in a new published study, Hazer et al [67]. found that random GH Levels $<2.33 \mu \mathrm{g} / \mathrm{L}$ after the 1 st day post operatively is a predictive of cure. Also, they found that the GH and IGF-I levels of these "uncured" cases decrease to the hormone levels of the cured cases (GH levels were between 0.4 and $1 \mu \mathrm{g} / \mathrm{L}$ ) at the 1-year follow-up. Also, Assaad et al. [42] studied the relationship between early (in the first week after surgery) postoperative basal GH concentration and long-term outcome of GH-producing pituitary adenoma, there was a significant relationship between the early postoperative basal GH concentration and long-term postoperative outcome $(\mathrm{p}<0.05)$. There is an important point that Hazer et al pointed out in there article, as they found that using the Strict guideline criteria of 2010 consensus several patients fail to attain a cure in short term according to the 2010 consensus criteria may however they fulfill these criteria in a longer follow-up period.

\section{Summary}

In the 10 years since the criteria for cure of acromegaly were defined by the Acromegaly Consensus Group, significant progress has been made in the management of acromegaly. If managed appropriately by a multimodality team with specific experience of managing pituitary tumors, there is little justification for patients to have reduced life expectancy, frequent morbidity, or uncontrolled disease. Challenges related to criteria of cure include the need to standardize GH and IGF-I assays, how to interpret discrepant biochemical results, and how to refine treatment with SRLs to optimize tumor shrinkage.

\section{References}

1. Cook DM, Ezzat S, Katznelson L (2004) AACE Medical Guidelines for Clinical Practice for the diagnosis and treatment of acromegaly. Endocr Pract 10(3): 213-225.

2. Colao A, Ferone D, Marzullo P, Lombardi G (2004) Systemic complications of acromegaly: epidemiology, pathogenesis, and management. Endocr Rev 25(1): 102-152.

3. Katznelson L, Atkinson JL, Cook DM, Ezzat SZ, Hamrahian AH, et al. (2011) American Association of Clinical Endocrinologists medical guidelines for clinical practice for the diagnosis and treatment of acromegaly--2011 update. Endocr Pract 17(4): 1-44.

4. Giustina A, Barkan A, Chanson P (2008) Guidelines for the treatment of growth hormone excess and growth hormone deficiency in adults. J Endocrinol Invest 31(9): 820-838.

5. Melmed S, Colao A, Barkan A, Molitch M, Grossman AB, et al. (2009) Guidelines for acromegaly management: an update. J Clin Endocrinol Metab 94(5): 1509-1517.

6. Buchfelder M, Schlaffer S (2009) Surgical treatment of pituitary tumours. Best Pract Res Clin Endocrinol Metab 23(5): 677-692.

7. Roelfsema F, Biermasz NR, Pereira AM (2012) Clinical factors involved in the recurrence of pituitary adenomas after surgical remission: a structured review and meta-analysis. Pituitary 15(1): 71-83.

8. Kim EH, Oh MC, Lee EJ, Kim SH (2011) Predicting long term remission by measuring immediate postoperative growth hormone levels and oral glucose tolerance test in acromegaly. Neurosurgery 70(5): 1106111.

9. Krieger MD, Couldwell WT, Weiss MH (2003) Assessment of long-term remission of acromegaly following surgery. J Neurosurg 98(4): 719724.

10. Giustina A, Barkan A, Casanueva FF, Cavagnini F, Frohman L, et al. (2000) Criteria for cure of acromegaly: a consensus statement. J Clin Endocrinol Metab 85(2): 526-529 
11. Melmed S, Jackson I, Kleinberg D, Klibanski A (1998) Current treatment guidelines for acromegaly. J Clin Endocrinol Metab 83: 2646-2652.

12. Irie M, Tsushima $T$ (1972) Increase of serum growth hormone concentration following thyrotropin-releasing hormone injection in patients with acromegaly or gigantism. J Clin Endocrinol Metab 35: $97-$ 100.

13. Gelato MC, Merrian GR, Vance ML, Goldman JA, Webb C, et al. (1985) Effects of growth hormone releasing factor on growth hormone secretion in acromegaly. J Clin Endocrinol Metab 60: 251-257.

14. Melmed S, Casanueva FF, Cavagnini F, Chanson P, Frohman L, et al. (2002) Guidelines foracromegaly management. J Clin Endocrinol Metab 87: 4054-4058.

15. Melmed S, Casanueva F, Cavagnini F, Chanson P, Frohman LA, et al. (2005) Consensus statement: medical management of acromegaly. Eur J Endocrinol 153: 737-740.

16. Giustina A, Casanueva FF, Cavagnini F, Chanson P, Clemmons D, et al. (2003) Diagnosis and treatment of acromegaly complications. J Endocrinol Invest 26:1242-1247.

17. Giustina A, Chanson P, M D Bronstein, A Klibanski, S Lamberts, et al. (2010) A Consensus on Criteria for Cure of Acromegaly. J Clin Endocrinol Metab 95: 3141-3148.

18. Pokrajac A, Wark G, Ellis AR, Wear J, Wieringa GE, et al. (2007) Variation in GH and IGF-I assays limits the applicability of international consensus criteria to local practice. Clin Endocrinol (Oxf) 67(1): 65-70.

19. Bidlingmaier M (2008) Problems with GH assays and strategies toward standardization. Eur J Endocrinol 159(1): S41-S44.

20. Arafat AM, Moehlig M, Weickert MO, Perschel FH, Purschwitz J, et al. (2008) Growth hormoneresponse during oral glucose tolerance test: the impact of assay method on the estimation of reference values in patients with acromegaly and in healthy controls, and the role of gender, age, and body mass index. J Clin Endocrinol Metab 93: 12541262.

21. Melmed S (2006) Medical progress: acromegaly. N Engl J Med 355(24): 2558-2573.

22. TrainerPJ, Barth J, Sturgeon C, Wieringaon G (2006) Consensusstatement on the standardisation of GH assays. Eur J Endocrinol 155(1): 1-2.

23. Clemmons DR (2007) Value of insulin-like growth factor system markers in the assessment of growth hormone status. Endocrinol Metab Clin North Am 36(1): 109-129.

24. Sneppen SB, Lange M, Pedersen LM, Kristensen L LØ, Main KM, et al (2001) Total and free Insulin-like growth factor I, insulin-like growth factor binding protein 3 and acid-labile subunit reflect clinical activity in acromegaly. Growth Horm IGF Res 11(6): 384-391.

25. Juul A (2003) Serum levels of insulin-like growth factor I and its binding proteins in health and disease. Growth Horm IGF Res 13(4): 113-170.

26. Carmichael JD, Bonert VS, Mirocha JM, Melmed S (2009) The utility of oral glucose tolerance testing for diagnosis and assessment of treatment outcomes in 166 patients with acromegaly. J Clin Endocrino Metab 94: 523-527.

27. Minuto F, Resmini E, Boschetti M, Arvigo M, Sormani MP, et al. (2004) Assessment of disease activity in acromegaly by means of a single blood sample: comparison of the 120th minute postglucose value with spontaneousGHsecretion and with the IGF system. Clin Endocrinol (Oxf) 61: 138-144.

28. Ho KY, Weissberger AJ (1994) Characterization of 24-hour growth hormone secretion in acromegaly: implications for diagnosis and therapy. Clin Endocrinol (Oxf) 41: 75-83.
29. Reutens AT, Veldhuis JD, Hoffman DM, Leung KC, Ho KK (1996) A highly sensitive growth hormone (GH) enzyme-linked immunosorbent assay uncovers increased contribution of a tonic mode of GH secretion in adults with organic GH deficiency. J Clin Endocrinol Metab 81: 15911597.

30. Alexopoulou O, Bex M, Abs R, T'Sjoen G, Velkeniers B, et al. (2008) Divergence between growth hormone and insulin-like growth factor-1 concentrations in the follow-up of acromegaly. J Clin Endocrinol Metab 93: $1324-1330$

31. Freda PU (2009) Monitoring of acromegaly: what should be performed when GH and IGF-1 levels are discrepant? Clin Endocrinol (Oxf) 71: 166-170.

32. van der Klaauw AA, Pereira AM, van Thiel SW, Frolich M, Iranmanesh A, et al. (2007) Attenuated pulse size, disorderly growth hormone and prolactin secretion with preserved nyctohemeral rhythm distinguish irradiated from surgically treated acromegaly patients. Clin Endocrinol (Oxf) 66: 489-498.

33. Feelders RA, Bidlingmaier M, Strasburger CJ, Janssen JA, Uitterlinden $P$, et al. (2005) Postoperative evaluation of patients with acromegaly: clinical significance and timing of oral glucose tolerance testing and measurement of (free) insulin-like growth factor I, acidlabile subunit, and growth hormone-binding protein levels. J Clin Endocrinol Metab 90(12): 6480-6489.

34. Melmed S, F F Casanueva, A Klibanski, M D Bronstein, P Chanson, et al. (2013) A consensus on the diagnosis and treatment of acromegaly complications. Pituitary 16(3): 294-302.

35. Holdaway IM, Bolland MJ, Gamble GD (2008) A meta-analysis of the effect of lowering serum levels of GH and IGF-I on mortality in acromegaly. Eur J Endocrinol 159(2): 89-95.

36. Bihan H, Espinosa C, Valdes-Socin H, Salenave S, Young J, et al. (2004) Long-term outcome of patients with acromegaly and congestive heart failure. J Clin Endocrinol Metab 89(11): 5308-5313.

37. Abosch A, Tyrrell JB, Lamborn KR, Hannegan LT, Applebury CB (1998) Transsphenoidal microsurgery for growth hormone-secreting pituitary adenomas: initial outcome and longterm results. J Clin Endocrinol Metab 83: 3411-3418.

38. Ross DA, Wilson CB (1988) Results of transsphenoidal microsurgery for growth hormone-secreting pituitary adenoma in a series of 214 patients. J Neurosurg 68(6): 854-867.

39. Fahlbusch R, Honegger J, Buchfelder M (1992) Surgical management of acromegaly. Endocrinol Metab Clin North Am 21(3): 669-692.

40. Abbassioun K, Amirjamshidi M, Mehrazin A, Khalatbary I, Keynama M, et al. (2006) A prospective analysis of 151 cases of patients with acromegalyoperated by on neurosurgeon: a follow-up of more than 23 years. Surg Neurol 66(1): 26-31.

41. Beauregard C, Truong U, Hardy J, Serri O (2003) Long-term outcome and mortality after transsphenoidal adenomectomy for acromegaly. Clin Endocrinol (Oxf) 58(1): 86-91.

42. Assaad F, Tamer Al-Ameer T, Salma A (2016) Validity of immediate postoperative random $\mathrm{GH}$ level as a predictor factor of long-term control of GH- producing pituitary adenoma. Endocrinol Metab Int J 3(3): 00050.

43. Ciric I, Ragin A, Baumgartner C, Pierce D (1997) Complications of transsphenoidal surgery: results of a national survey, review of the literature, and personal experience. Neurosurgery 40: 225-236.

44. Freda PU, Wardlaw SL, Post KD (1998) Long-term endocrinological follow-up evaluation in 115 patients who underwent transsphenoidal surgery for acromegaly. J Neurosurg 89: 353-358. 
45. Swearingen B, Barker FG, Katznelson L et al. 1998 Long-term mortality after transsphenoidal surgery, and adjunctive therapy for acromegaly. J Clin Endocrinol Metab 83: 3419-3426.

46. Davis DH, Laws ER, Ilstrup MS, Speed JK, Caruso M, et al. (1993) Results of surgical treatment for growth hormone-secreting adenomas. J Neurosurg 79: 70-75.

47. Lamberts SWJ, Van der Lely A J, de Herder WW, Hofland LJ (1996) Octreotide. N Engl J Med 334: 246-254.

48. Newman C, Melmed S, George A, Torigian D, Duhaney M, et al. (1998) Octreotide as primary therapy for acromegaly. J Clin Endocrinol Metab 83(9): 3104-3109.

49. Lancranjan I, Atkinson AB, Sandostatin LAR Group. 1999 Results of a European multicentre study with Sandostatin LAR in acromegalic patients. Pituitary 1(2): 105-114.

50. Caron P, Morange-Ramos I, Cogne M, Jaquet P (1997) Three-year follow-up of acromegalic patients treated with intramuscular slowrelease lanreotide. J Clin Endocrinol Metab 82(1): 18-22.

51. Barkan AL, Halasz I, Dornfeld KJ, Jaffe CA, Friberg RD, et al. (1997) Pituitary irradiation is ineffective in normalizing plasma insulin-like growth factor I in patients with acromegaly. J Clin Endocrinol 82(10): 3187-3191.

52. Landolt AM, Haller D, Lomax N, Scheib S, Schubiger O, et al. (1998) Stereotactic radiosurgery for recurrent surgically treated acromegaly. comparison with fractionated radiotherapy. J Neurosurg 88(6): 10021008.

53. Nomikos P, Buchfelder M, Fahlbusch R (2005) The outcome of surgery in 668 patients with acromegaly using current criteria of biochemical cure. Eur J Endocrinol 152: 379-387.

54. Dimaraki EV, Jaffe CA, DeMott-Friberg R, Chandler WF, Barkan AL (2002) Acromegaly with apparently normal GH secretion: implications for diagnosis and follow-up. J Clin Endocrinol Metab 87: 3537-3542.

55. Freda PU, Post KD, Powell JS, Wardlaw SL (1998) Evaluation of disease status with sensitive measures of growth hormone secretion in 60 postoperative patients with acromegaly. J Clin Endocrinol Metab 83 3808-3816.

56. Trainer PJ, DrakeWM, Katznelson L, Freda PU, Herman-Bonert V, et al. (2000) Treatment of acromegaly with the growth hormone-receptor antagonist pegvisomant. NEngl JMed 342: 1171-1177.

57. Kaltsas GA, Isidori AM, Florakis D, Trainer PJ, Camacho-Hubner C, et al. (2001) Predictors of the outcome of surgical treatment in acromegaly

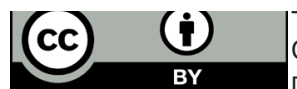

This work is licensed under Creative Commons Attribution 4.0 Licens

DOI: $10.19080 / J E T R ~ 2019.04 .555647$ and the value of the mean growth hormone day curve in assessing postoperative disease activity. J Clin Endocrinol Metab 86:1645-1652.

58. Attanasio R, Lanzi R, Losa M, Valentini F, Grimaldi F, et al. (2008) Effects of lanreotide Autogel on growth hormone, insulin like growth factor 1 , and tumor size in acromegaly: a 1-year prospective multicenter study. Endocr Pract 14 :846-855.

59. Colao A, Pivonello R, Auriemma RS, Briganti F, Galdiero M, et al. (2006) Predictors of tumor shrinkage after primary therapy with somatostatin analogs in acromegaly: a prospective study in 99 patients. J Clin Endocrinol Metab 91: 2112-2118.

60. Cozzi R, Montini M, Attanasio R, Albizzi M, Lasio G, et al. (2006) Primary treatment of acromegaly with octreotide LAR: a long-term (up to nine years) prospective study of its efficacy in the control of disease activity and tumor shrinkage. J Clin Endocrinol Metab 91: 1397-1403

61. Melmed S, Sternberg R, Cook D, Klibanski A, Chanson P, et al. (2005) A critical analysis of pituitary tumor shrinkage during primary medical therapy in acromegaly. J Clin Endocrinol Metab 90: 4405-4410.

62. Colao A, Auriemma RS, Rebora A, Galdiero M, Resmini E, et al. (2009) Significant tumour shrinkage after 12 months of lanreotide Autogel-120 mg treatment given first line in acromegaly. Clin Endocrinol (Oxf) 71: 237-245.

63. Amato G, Mazziotti G, Rotondi M, Iorio S, Doga M (2002) Long-term effects of lanreotide SR and octreotide LAR on tumour shrinkage and GH hypersecretion in patients with previously untreated acromegaly. Clin Endocrinol (Oxf) 56: 65-71.

64. Gola M, Bonadonna S, Mazziotti G, Amato G, Giustina A (2006) Resistance to somatostatin analogs in acromegaly: an evolving concept? J Endocrinol Invest 29: 86-93.

65. Abe T, Lu decke DK (2001) Effects of preoperative octreotide treatment on different subtypes of $90 \mathrm{GH}$-secreting pituitary adenomas and outcome in one surgical centre. Eur J Endocrinol 145: 137-145.

66. Carlsen SM, Lund-Johansen M, Schreiner T, Aanderud S, Johanneseno, (2008) Preoperative octreotide treatment in newly diagnosed acromegalic patients with macroadenomas increases cure short-term postoperative rates: a prospective, randomized trial. J Clin Endocrinol Metab 93: 2984-2990.

67. Hazer D, Işık S, Berker D, Güler S, Gürlek A (2013) Treatmen of acromegaly by endoscopic transsphenoidal surgery: surgical experience in 214 cases and cure rates according to current consensus criteria. J Neurosurgery 119(6): 1467-1477.

Your next submission with Juniper Publishers
will reach you the below assets
- Quality Editorial service
- Swift Peer Review
- Reprints availability
- E-prints Service
- Manuscript Podcast for convenient understanding
- Global attainment for your research
- Manuscript accessibility in different formats
( Pdf, E-pub, Full Text, Audio)
- Unceasing customer service
Track the below URL for one-step submission
https://juniperpublishers.com/online-submission.php

